\title{
P63 expression profile in uterine cervical lesions
}

Accepted: 5/5/2019

Yusra Abdulkhaliq Qasim ${ }^{1 *}$

\begin{abstract}
Background and objective: P63 is a member of the p53 gene family. It plays an essential role in the normal development of the cervix. This study aimed to assess p63 expression in different cervical lesions and the correlation between their expression in cervical intraepithelial neoplastic changes and invasive cervical cancer.

Methods: A total of 62 cervical tissues were performed for p63 immunostaining, including 15 samples of non-neoplastic reactive cervicitis, 27 cervical intraepithelial neoplastic changes, and 15 invasive cervical cancer cases as well as five samples of normal cervical tissue as control.
\end{abstract}

Results: P63 in normal cervical squamous epithelium had restricted staining pattern in the nuclei of basal cells. Reactive cervicitis staining ranged from restricted staining pattern in basal cells to mild increase in staining intensity involving upper parabasal cells. P63 was positive in all CIN lesions, and staining intensity increased significantly with increasing severity of cervical intraepithelial lesions compared with non-neoplastic epithelium. All cervical squamous cell carcinoma had high staining intensity while adenocarcinoma and small cell carcinoma were stained negative.

Conclusion: P63 can be used as a marker for the distinction between reactive cervicitis and cervical intraepithelial changes. It is also of value for grading of CIN lesions and differentiation between squamous cell carcinoma, adenocarcinoma, and small cell carcinoma.

Keywords: P63 immunostaining; Cervical squamous cell carcinoma.

\section{Introduction}

P63 gene is a member of the p53 gene family. In normal tissues, p53 levels are undetectable and only reach significant levels after genotoxic stress or mutational inactivation causing p53 protein stabilization. In contrast, p63 exhibits a strikingly varied expression pattern in normal tissues. It is expressed at high levels in many normal epithelium squamous epithelium including urothelium and prostate. ${ }^{1} \mathrm{P} 63$ plays a crucial role in epithelial cell regeneration and renewal. It has emerged as a critical player in embryonic development, epithelial stem cell maintenance, and differentiation. ${ }^{2}$ Upon the maturation of normal stratified squamous epithelium, p63 protein expression gets down-regulated, and p63 protein is rarely detected in upper layers of the normal epithelium. ${ }^{3}$ However, upon dysplastic change, above the basal layers may serve to prevent basal cells from differentiating and thereby helps to maintain their basal cell status. ${ }^{4}$ The development of squamous cell carcinoma SCC is a multistep process requiring the accumulation of multiple genetic alterations, influenced by environmental factors including tobacco, alcohol, chronic inflammation, and viral infection. ${ }^{5}$ Precancerous lesions usually precede SCC clinically. At the microscopic level, these lesions show varying degrees of epithelial dysplasia, from mild to severe. A higher grade of dysplasia is generally 
associated with a higher risk of neoplastic transformation. ${ }^{6}$ A number of molecular markers have been identified over the years to detect the transition from normal epithelium to the premalignant and malignant epithelium. P63 is helpful in determining the nature of the progression of a lesion, whether the metaplasia is due to inflammation or atypical change. High P63 expression indicates a neoplastic progression. ${ }^{7,8}$ Cervical intraepithelial neoplasia CIN is a dysplastic process in the cervical squamous epithelium and carries a risk of progression to cervical cancer; it is usually a long pre-invasive process, which over time can progress to invasive cervical carcinoma. ${ }^{9}$ The $\mathrm{WHO}$ classification applied Low-grade Squamous Intraepithelial Lesion LSIL and High-grade Squamous Intraepithelial Lesion HSIL terminology to the previous classifications as CIN I, CIN II and CIN III based on the degree of dysplasia. Accurate histological grading of CIN lesions was important for clinical management of patients because CIN lesions were monitored and treated differently. ${ }^{10}$ Cervical intraepithelial neoplastic lesion CIN I usually regress in about $80 \%$ of cases, while CIN II and CIN III were regarded as precursors of invasive carcinomas. ${ }^{11}$ Diagnosis and prediction of progression risk were important issues in the clinical management of patients with $\mathrm{CIN}$; identification of specific biomarkers for CIN diagnosis is of particular importance. ${ }^{12,13}$ This study aimed to assess p63 expression in different cervical lesions and find the association among their expression in $\mathrm{CIN}$ and invasive cervical cancer and assess the role of P63 in grading intraepithelial neoplastic changes.

\section{Methods}

Range of malignant and potentially malignant cervical lesions and inflammatory reactive cervicitis were included in this cross-sectional study. A total of 62 cases were selected from Maternity Teaching Hospital and some private laboratories in Erbil, Kurdistan Region, Iraq, from January 2014 to December 2015. The non-neoplastic reactive cervicitis cases were 15 . The CIN lesions were 27, including $10 \mathrm{CINI}$, $7 \mathrm{CINII}$, and $10 \mathrm{CINIII}$. There were 15 invasive cervical cancer cases, including 11 squamous cell carcinoma (SCC), 3 adenocarcinoma and 1 small cell carcinoma. Also, 5 normal cervical tissues were collected from patients undergoing hysterectomy, due to abnormalities in the uterus and considered a control group. Formalin-fixed, paraffin-embedded tissue sections were cut at $5 \mu$ and stained using the standard immunohistochemical methodology. All samples were stained for immunohistochemical study with DAKO kit foranti-p63 antibody (1:100) for all slides using the streptavidin-biotin- peroxidase technique. Negative external control staining was done by omitting primary antibodies, and for positive external control, prostatic glandular tissue was used. ${ }^{1}$ Patients with $\mathrm{CIN}$ changes, malignant cervical cancer, and females aged above 18 years old were included in this study. Female with severe genital tract infection, patients with a history of radiotherapy, and or hormonal therapy were excluded from the study.

\section{Evaluation and Interpretation of P63 immunostaining:}

P63 was analyzed individually and also in combination with corresponding Hematoxylin and Eosin $\mathrm{H}$ and $\mathrm{E}$. stained slides. To determine the location and proportion of positive, the presence of brown-colored end products at the site of the target antigen (nucleus) was considered as positive. The immunostaining of p63 was judged as positive when more than $10 \%$ of the cell nuclei showed a strong intensity. ${ }^{14,15}$ Immunohistochemical reactions were quantified by means of the intensity of the reaction and the percentage of marked cells, establishing a grading score ( $G$ score) for all parameters. 


\section{Scoring of $\mathrm{p} 63$}

The immunostaining was evaluated range from totally absent $(0)$ to weak (10) cell nuclei stained, and $>10$ cell nuclei stained. The positive staining intensity was scored as weak but definite positive $(1+)$, moderate $(2+)$, and strong $(3+) .{ }^{15,16}$ Weak positive (score 1) $>10-25 \%$, moderate positive (score 2) $26-75 \%$ and strong positive (score 3) 76-100\%. The expression level of p63 (reflected in the mean IHC score) was exhibited in each studied groups (Group 1= reactive cervicitis, Group $2=\mathrm{CIN}$ lesion, and Group $3=$ cervical cancer cases). ${ }^{7}$ This study was approved by the ethical commute of Hawler Medical University.

\section{Statistical analysis}

The statistical package for the social sciences (SPSS, version 21) was used for data analysis. The ANOVA test was used for the analysis of variance to compare the means. Tukey HSD Post hoc test was used to study the association between the studied groups and p63 expression level. Fisher's exact test was used for differences between age groups. A $P$ value of $<0.05$ was regarded as significant.

\section{Results}

The mean age \pm SD for reactive cervicitis was $36.1 \pm$ SD 5.3 years, ranged from 29 to 43 years, CIN1 was $38.7 \pm 6.5$ years ranged from 30 to 45 years, CINII was $46.14 \pm 5.9$ years ranged from 36 to 52 years, CIN III was $51.8 \pm 4.9$ years ranged from 45-58 years and for cervical carcinoma $56.2 \pm 6.2$ years, ranged from 45-68 years. The p63 expression was $83.3 \%$ among patients $\geq 50$,compared with $69.7 \%$ among those aged less than 50 , but the difference was not significant $(P=0.35)$, as shown in Table 1 .

\section{Distribution and scoring of P63}

Normal and non-neoplastic cervical epithelium:

All normal cervical tissue showed negative p63 immunostaining (score $\leq 10 \%$ ), while reactive cervicitis showed positive p63 immunostaining in $5 / 15(33 \%)$ with a mean of (8.8 \pm SD 3.0206), but with low score p63 expression (>10-25\%). In these cases, a maximum intensity reaction was detected in the nuclei of basal epithelial cells, which was diminished and absent towards the surface epithelium in the nuclei of mature cells.

Cervical intraepithelial lesions and cervical cancer cases:

All CIN lesions (27) cases were positive for p63 (100\%), with positive homogenous nuclear staining pattern but with variable scores. In comparison with reactive cervicitis, p63 immunoexpression was higher in all samples of CIN epithelium. CIN III showed the highest score p63 immunoexpression with a value above $75 \%$, while only 2 cases $(28.7 \%)$ of CINII had high score p63 immunoexpression (score 3) and the score for p63 immunoexpression of the remaining 5 cases $(71.4 \%)$ was 2. All CIN I had a moderate score. The positivity of p63 increased significantly with the increasing severity of cervical dysplasia. All cases of SCC showed higher p63 score expression while all cases of non-SCC were negative, including three cases adenocarcinoma and one case small cell carcinoma. The distribution of p63 in different cervical tissue is shown in Figure1. 
P63 expression profile in uterine cervical lesions ......

Zanco J. Med. Sci., Vol. 24, No. (2), August, 2020 https://doi.org/10.15218/zjms.2020.023

Table 1: P63 expression status in relation to age in various cervical lesions.

\begin{tabular}{lcccc}
\hline Age (years) & $\begin{array}{c}\text { Positive P63 } \\
\text { No.(\%) }\end{array}$ & $\begin{array}{c}\text { Negative P63 } \\
\text { No.(\%) }\end{array}$ & Total & $P$ value \\
\hline$<50$ & $23(69.7 \%)$ & $10(30.3 \%)$ & $33(100)$ & 0.35 \\
$\geq 50$ & $20(83.3 \%)$ & $4(16.66 \%)$ & $24(100)$ & \\
Total & $43(75.43 \%)$ & $14(24.56 \%)$ & $57(100)$ & \\
\hline
\end{tabular}
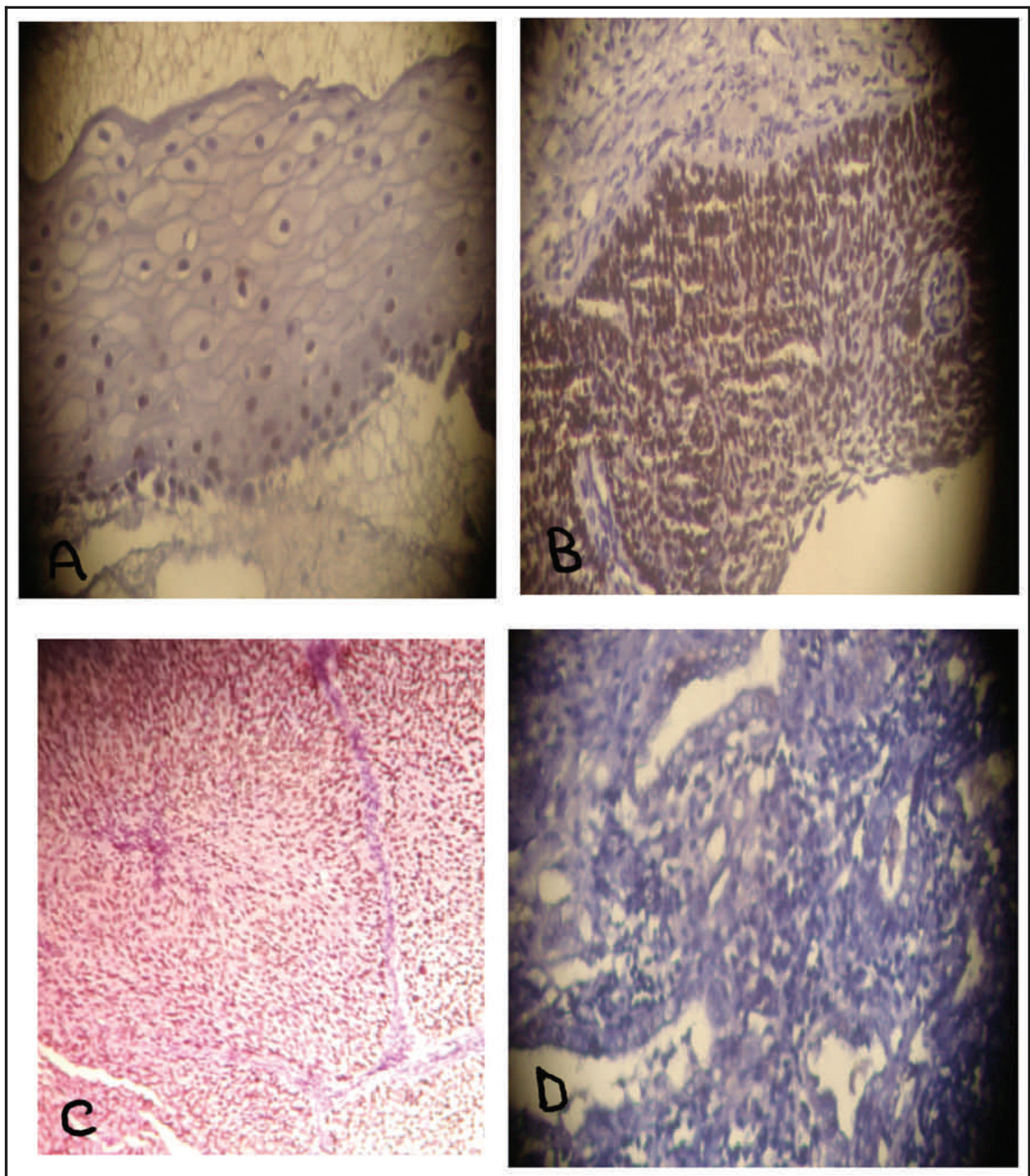

Figure 1: Distribution of p63 in different cervical tissue.

(A) P63 expression in normal cervix $\times 200$ (Prominent nuclear staining in basal layer)

(B) P63 expression in CIN III x200 intense nuclear staining among whole mucosal thickness)

(C) P63 expression in invasive SCC $\times 100$

(D) P63 expression in adenocarcinoma x 400(negative nuclear p63 immunoexpression) 
Comparison of means p63 expression in CIN lesions and SCC with reactive cervicitis.

All CIN lesions showed a higher mean p63 expression being the highest in CIN III $(91.9 \pm 2.5144)$, followed by CIN II $(65.3 \pm 2.8702)$ and the lowest in CIN I (39.2 \pm 3.6148). For cervical carcinoma, SCC had the highest mean p63 among cervical lesions $(95.5 \pm 2.5495)$. There was a statistically significant difference between reactive cervicitis, CIN lesions, and SCC as determined by the one-way ANOVA test (Table 2). The positivity of p63 immunoexpression increases significantly with increasing severity of cervical dysplasia and SCC, as shown in Table 3. Moreover, there was a significant difference between CIN groups regarding p63 expression, as shown in Table 4.

Table 2: Mean p63 score between reactive cervicitis, CIN lesions, and SCC.

\begin{tabular}{lcccc}
\hline Type of lesion & No. & Mean P63 $(\%)$ & $\mathbf{\pm}$ SD & $P$ value \\
\hline Reactive cervicitis & 15 & 8.8 & 3.0206 & \\
CIN I & 10 & 39.2 & 3.6148 & $<0.001$ \\
CIN II & 7 & 65.3 & 2.8702 & \\
CLN III & 10 & 91.9 & 2.5144 & \\
SCC & 11 & 95.5 & 2.5495 & \\
\hline
\end{tabular}

Table 3: Comparison of mean p63 expression between reactive cervicitis, CIN lesions, and between CIN with SCC.

\begin{tabular}{ccccccccc}
\hline $\begin{array}{c}\text { Type of } \\
\text { lesion }\end{array}$ & $\begin{array}{c}\text { Mean } \\
\mathbf{P 6 3}( \pm \text { SD) }\end{array}$ & $\boldsymbol{P}$ value & $\begin{array}{c}\text { Type of } \\
\text { lesion }\end{array}$ & $\begin{array}{c}\text { Mean } \\
\mathbf{p 6 3}( \pm \mathbf{S D})\end{array}$ & $\boldsymbol{P}$ value & $\begin{array}{c}\text { Type of } \\
\text { lesion }\end{array}$ & $\begin{array}{c}\text { Mean p63 } \\
( \pm \mathbf{S D})\end{array}$ & $\boldsymbol{P}$ value \\
\hline $\begin{array}{c}\text { Reactive } \\
\text { cervicitis }\end{array}$ & $8.8(3.02)$ & $<0.001$ & $\begin{array}{c}\text { Reactive } \\
\text { cervicitis }\end{array}$ & $8.8(3.02)$ & $<0.001$ & $\begin{array}{c}\text { Reactive } \\
\text { cervicitis }\end{array}$ & $8.8(3.02)$ & $<0.001$ \\
CIN I & $39.2(3.6)$ & & CIN II & $65.3(2.9)$ & & CIN III & $91.9(2.5)$ & \\
CINI & $39.2(3.6)$ & 0.001 & CINII & $65.3(2.9)$ & 0.001 & CINIII & $91.9(2.5)$ & 0.005 \\
SCC & $95.5(2.54)$ & & SCC & $95.5(2.54)$ & SCC & $95.5(2.54)$ & \\
\hline
\end{tabular}

Table 4: Comparison of mean p63 expression between various CIN lesions.

\begin{tabular}{lcc}
\hline Type of lesions & Mean P63 (士SD) & P value \\
\hline CINI & $39.2(3.6)$ & $<0.001$ \\
CINII & $65.3(2.9)$ & \\
CINI & $39.2(3.6)$ & $<0.001$ \\
CINIII & $91.9(2.5)$ & \\
CINII & $65.3(2.9)$ & $<0.001$ \\
CINIII & $91.9(2.5)$ & \\
\hline
\end{tabular}




\section{Discussion}

Accurate diagnosis of $\mathrm{CIN}$ changes was an important issue in the clinical management of patients with $\mathrm{CIN} 1{ }^{14}$ In general, there tends to be poor inter and intra-observer reproducibility of CIN grade evaluation among pathologists. In particular, the differential diagnosis between immature squamous metaplasia and CIN1 and II, or between low-grade (CIN1) and high-grade (CINII and III) lesions, tends to be difficult. These difficulties mean that patients tend to be over-treated for CIN lesions; the need for alternative approaches and specific biomarkers to aid objective CIN lesions grading, and to identify true high-grade cervical disease. ${ }^{11}$ In the current study, the mean age of reactive cervicitis is younger than CIN patients and invasive cervical cancer, while no statistically significant association between p63 expression and patient's age was found. This is similar to a study done by Romus. ${ }^{17}$ The normal cervical epithelium and some reactive inflammatory cervical lesions were stained negative to p63. This absence p63 expression at the surface epithelium indicates normal maturation of the cervical epithelium and confirms the earlier results in which p63 expression follows a restricted pattern in normal tissues and is expressed in basal cells but is rapidly degraded upon their differentiation. ${ }^{3}$ Other studies based on immunohistochemical data, showed that p63 protein is expressed in the proliferative layer of cells near the basement membrane of the normal mucosa, where it likely serves to prevent basal cells from differentiating and thereby helps to maintain their basal cell status. ${ }^{4,6}$ Various p63 staining, according to $G$ score was seen, with a significant correlation was found between p63 overexpression in CINI and the lowest $G$ score in reactive cervicitis. In this study, five inflammatory reactive cervicitis were stained positive to p63 with a mild degree or weak score intensity. This may be due to immature squamous metaplasia associated with parabasal cell hyperplasia related to inflammation and reactive changes. Although these cases were stained positive, they are unlikely to be scored as $\mathrm{CINI}$ by IHC grading because their mean score is lower than the mean score for CINI. This finding confirmed by other studies that indicated that p63 gene is preferentially expressed in basal and immature cervical squamous epithelium and the reactive epithelial changes, which is usually associated with inflammation, pregnancy, and hormonal therapies, which can mimic CIN. ${ }^{18,19}$ Research results indicate that p63 is a reliable biomarker to distinguish reactive changes from CIN I. ${ }^{14,20}$ The current study found that the p63 immunoexpression was increasing significantly with the increase in the grade of CIN. Many studies have analyzed p63 expression in $\mathrm{CIN}$ and reported that p63 expression was concordantly increased according to the degree of dysplasia., $3,4,14,20$ Association of p63 in CIN lesions with histologically confirmed and graded slides by $\mathrm{H}$ and $\mathrm{E}$ showed that all $\mathrm{CIN}$ were in accordance, a part from two cases of CINII, which by p63 was changed to high grade (score 3 ). It should be emphasized that IHC study should always, as far as possible, correlate with morphology, especially in equivocal cases. This is in accordance with Houghton et al., who concluded that when morphology and IHC are discordant, the interpretation should be cautious, repeated, and reviewed by a second pathologist. ${ }^{21}$ Many reviewers agree that p63 is of great value in the distinction between CIN I, CIN II and CIN III. ${ }^{14,15}$ The results of this study suggest that molecular changes occur in the cervical mucosa. The expression of p63 has been demonstrated in squamous cell carcinomas of the cervix. This emphasizes the role of p63 in cervical tumourigenesis, which is in parallel to other studies., ${ }^{3,5,7}$ Finally, all cervical carcinomas other than SCC, including all adenocarcinomas cases and small cell carcinoma, were entirely negative for p63. Many previous studies agreed that p63 
is useful as a powerful marker for squamous differentiation and, when diffusely expressed, excludes a glandular or neuroendocrine differentiation. ${ }^{22}$ This study is limited by having a small number of control cases due to increased costs.

\section{Conclusion}

P63 can be used as a marker for the distinction between reactive cervicitis and cervical intraepithelial changes; also, it is of value for grading of CIN lesions and differentiation between squamous cell carcinoma, adenocarcinoma, and small cell carcinoma.

\section{Competing interests}

The author declares no competing interests.

\section{References}

1. Koyuncuer A. Immunohistochemical expression of p63, p53 in urinary bladder carcinoma. Indian $\mathrm{J}$ Pathol Microbiol 2013; 56(1):10-5.

2. Inoue K, Fry, EA. Alterations of p63 and p73 in human cancers. SubcellBiochem2014; (85)17-40.

3. Abilasha R, Ramani P, Sherlin H J, Premkumar P, Natesan A. Immunohistochemical evaluation of oral epithelial dysplasia using cyclin-D1, p27 and p63 expression as predictors of malignant transformation. Nat Sci Biol Med 2013; 4(2):349_ 58.

4. Sharada $P$, Swaminathan $U$, Nagamalini $B$ R, Vinodkumar K, Ashwini B K, Lavanya V. A Semiquantitative analysis of immunohistochemical expression of p63, Ki-67, Cyclin-D1, and p16 in common oral potentially malignant disorders and oral squamous cell carcinoma. Journal of Dr. NTR University of Health Sciences 2018; 7(2):120 -8 .

5. Shetty S, Krishnapillai R, Prabhu S. Assessment and comparison of p53 and p63 expression in oral epithelial dysplasia and squamous cell carcinoma. SRM Journal of Research in Dental Sciences 2014; 5(3):149-54.

6- Mohite DP, Hande AH, Gupta R, Chaudhary MS, Palit S, Gawandi M. Immunohistochemical evaluation of expression pattern of P53, P63 and P73 in epithelial dysplasia. Journal of Data Meghe Institute of Medical Science University 2018; 13(3):122-9.

7. Jacob AA, Sundaram A. P16, Ki67 and P63 staining pattern in squamous metaplasia, CIN and cervical cancer. Int J Res Med Sci 2018; 6(3):882.

8. Saritha VN, Veena VS, Krishna J, Somanathan T, Sujathan K. Significance of DNA Replication
Licensing Proteins (MCM2, MCM5 and CDC6), p16 and p63 as Markers of Premalignant Lesions of the Uterine Cervix: Its Usefulness to Predict Malignant Potential. Asian Pacific Journal of Cancer Prevention 2017; 19(1):141-58.

9. Kurman RJ, Carcangiu ML, Herrington CS, Young $\mathrm{RH}$. WHO Classification of tumours. $4^{\text {th }}$ ed. Lyon: WHO; 2014.

10. Martin CM, O'Leary JJ, Phil D. Histology of cervical intraepithelial neoplasia and the role of biomarkers. Best Pract Res Clin Obstetgynaecol 2011; 25:605-15.

11. Díaz $C M G$, Rincón $A E S$, Camacho $G V$, Vázquez G B, Quintana SR, Wentzensen N, et al. P16INK4a immunohistochemistry improves the reproducibility of the histological diagnosis of cervical intraepithelial neoplasia in cone biopsies. Gynecol Oncol 2008; 111:120-4.

12. Van Niekerk D, Guillaud M, Matisic J, Benedet JL, Freeberg Ja, Follen M, et al. P16 and MIB1 improve the sensitivity and specificity of the diagnosis of high grade squamous intraepithelial lesions: methodological issues in a report of 447 biopsies with consensus diagnosis and $\mathrm{HPV} \mathrm{HCll}$ testing. Gynecol Oncol 2007; 107:233-40.

13. Lobato S, Tafuri A, Fernandes PÁ, Caliari Mv, Silva MX, Xavier Ma, et al. Maintenance 7 protein is a reliable biological marker for human cervical progressive disease. J Gynecol Oncol 2012; 23:11-5.

14. Mitildzans A, Arechvo A, Rezeberga D, Isajevs S. Expression of p63, p53 and $\mathrm{Ki}-67$ in Patients with Cervical Intraepithelial Neoplasia. Turk Patoloji Derg 2017; 33:9-16.

15. Kim SU, Lee JU, Lee DW, Kim MJ, Lee HN. The prognostic significance of $\mathrm{P} 16, \mathrm{KI} 67$, P63 and CK 17 expression determined by immunohistochemical staining in cervical intraepithelial I. Korean J Obstet Gynecol 2011; 54(4):184-91.

16. AbdRaboh NM, Hakim SA. Diagnostic role of DOG1 and p63 immunohistochemistry in salivary gland carcinomas. Int J Clin Exp Pathol 2015; 8(8):9214-22.

17. Romus I, Triningsih FE, Mangunsudirdjo S, Harijadi A. Clinicopathology significance of p53 and p63 expression in Indonesian cervical squamous cell carcinomas. J Cancer Prev 2013; 14(12):7737-41.

18. DasL,Naskar S, Sarkar T, Kumar A, Das S, Chatterjee J. Immunohistochemical evaluation of prime molecules in cervical lesions towards assessment of malignant potentiality. J Cancer Res Ther 2018; 14(2):377-81

19. KalofAN, Cooper K. Our approach to squamous intraepithelial lesions of the uterine cervix. J Clin Pathol 2007; 60(5):449-455.

20. Lin Z, Liu M, Li Z, Kim C, Lee E, Kim I. Protein expression in uterine cervical and endometrial cancers. J Cancer Res Clin Oncol 2006; 132:811 -6 . 
P63 expression profile in uterine cervical lesions ......

Zanco J. Med. Sci., Vol. 24, No. (2), August, 2020 https://doi.org/10.15218/zjms.2020.023

21. Houghton OI, McCluggage WG.The expression and diagnostic utility of p63 in the female genital tract. Adv Anat Pathol 2009; 16(5):316-21.

22. Glenn W. Immunohistochemistry as a diagnostic aid in cervical pathology. Pathology 2007; 39(1):97-111. 